Soriano, C. R. R. \& Gaw, F. (In press). Platforms, alternative influence, and networked political brokerage on YouTube. Convergence. The International Journal of Research into New Media Technologies.

\title{
Platforms, alternative influence, and networked political brokerage on YouTube
}

Cheryll Ruth R. Soriano ${ }^{1}$ and Fatima Gaw ${ }^{2}$

\begin{abstract}
This article interrogates political brokerage on YouTube by examining the platform's role in the construction of political discourses and in configuring the action of a new genre of political actors advancing a political agenda through historical revisionism. Using assemblage theory and drawing from technography (Bucher, 2018), we propose the concept of 'networked political brokerage' to characterize the mutually affirming relationship of YouTube's governance mechanisms and alternative political influencers' microcelebrity practices in building, complementing, and magnifying historical revisionist narratives through and within a network of algorithmically-sanctioned videos. We illustrate how this interplay of platform logics and cultures of use (Rieder et al., 2018) privileges and legitimizes political content into knowledge without accountability. We argue for the importance of examining YouTube as a socio-technical driver of this political brokerage process in curating political information in this contemporary political scene.
\end{abstract}

Keywords: YouTube; assemblage; brokerage; politics; historical revisionism

\section{Introduction}

YouTube has brought into the public scene diverse creative expressions of social, cultural, and political interest. Scholars and the media have directed the spotlight on the role of YouTube as a 'political influencer' (Lewis, 2019; Sucio, 2019) in the international and local political arena, and even as a driver of 'political radicalization' (Fisher and Taub, 2019; Dagle and Fallorina, 2019). This is, in part, enabled by its platform affordances and logics that facilitate the creation, curation and engagement of political

\footnotetext{
${ }^{1}$ Professor, Department of Communication, De La Salle University

${ }^{2}$ Assistant Professor, College of Mass Communication, University of the Philippines Diliman
} 
content, produced and participated by YouTube users and content creators. Among them are microcelebrities (Marwick, 2015) as emerging political actors in the platform, who build their own 'alternative influence networks' (Lewis, 2019) by capitalizing on YouTube's pervasive do-it-yourself creative culture. While both the platform affordances and logics and the rise of micro-influencers contribute to the political influence amassed by YouTube, there is a need to examine their intersections as they participate in complex political processes. We engage the concept of 'brokerage' (Stovel and Shaw, 2012) - often used in the context of traditional communicative forms that facilitate economic and political transactions-to characterize and highlight the governance mechanisms of YouTube vis-a-vis the often unseen performances of amateur political actors.

In interrogating the engagement between the platform and its users in this political brokerage process, this article examines the role of YouTube in configuring the construction of political discourses in the platform, as well as the strategies of a genre of political actors leveraging the platform's affordances and governance structure. We propose the concept of 'networked political brokerage' to pertain to the interconnected nature of the brokerage role of YouTube and these emerging influencers in bridging politics, history, and local audiences while being able to advance a monetary and political agenda. Using assemblage theory, we argue that it is the interplay of YouTube's affordances and recommendation system with the brokers' strategic use of the platform that privileges them with visibility and renders relevance to their narratives that together curate political and historical information in this contemporary political scene. We foreground the ways in which networked political brokerage is enacted and imbued with meaning as people engage in their YouTube-mediated socio-political world.

We explore the Philippines as an empirical case not only because of the record 
high subscription of YouTube in the country (We Are Social, 2018) but also that its growing population of 109 million is considered as one of the top markets for YouTube, with the number of channels with more than one million subscribers increasing 10 times from 2016 to 2019 (Mercurio, 2019). We focus on the case of historical revisionist discourse on the late Philippine President Ferdinand Marcos and his authoritarian regime because of documented "political conjectures and scholarly disjunctures" (Aguilar, 2019: 3) surrounding it. Because of vehement contestation of Marcos loyalists of institutionsanctioned historical narratives, historical information about Marcos and his administration remain floating and unsettled. A complicating factor is the fact that pertinent scholarly works on history are often inaccessibly written and not easily available to the general public. Since Marcos' death, there have been ongoing attempts to reconstruct his legacy from well-evidenced atrocities of Martial Law, ill-gotten wealth and cronyism, and economic crisis (Bautista, 2019). It is important to note that despite significant documentation connecting the Marcos' to massive corruption, torture, and other human rights violations (Official Gazette, 2015), the Marcos family continue to be political power holders, having been elected to important national and local positions for the last 20 years and with Marcos' son, Ferdinand Jr 'Bongbong', running for the vice presidency in the 2016 elections. President Rodrigo Duterte, who has openly expressed support for the Marcos family, further created a political atmosphere for revisionist narratives to thrive. While these political, economic and social conditions are themselves conducive to historical and political revisionism, micro-influencers emerge as an important political category as they work to mainstream political-historical narratives due to their relatability to mass audiences.

Through the lens of networked brokerage, we hypothesize how Philippine politics and history will be further reconfigured by new faces created and influenced by an 
ongoing production and circulation of unregulated political and historical content on social media platforms such as YouTube. Amateur political actors are often dismissed or "underestimated in discourse on the rise of disinformation" (Lewis, 2019: 5), but we see this as unable to capture the complexity, nuance, and 'greyness' of the nature of political engagement by these actors on YouTube. We extend existing analysis that explores 'cultures of use' (Rieder et al., 2018) to encapsulate the culture of brokerage on YouTube and the role of the platform in not only disseminating but also financially incentivizing hyper-partisan propaganda, historical revisionism, and conspiracy theories (see also Lewis, 2019; Ong, Tapsell and Curato, 2019). Brokering has now been deeply internalized and constantly negotiated by individuals who perceive YouTube as a fundamental source of investment, mobility, networks, and capital, possibly implying the importance of recalibrating how we think about the tensions and complex overlaps between political engagement and manipulation, legitimate and illegitimate content, knowledge creation and disinformation, and how we can imagine possible interventions.

\section{Socio-technical process of brokerage: Platforms, microcelebrities and networked assemblage of visibility and control}

\section{Traditions of political brokerage}

The concept of brokerage has been a critical lens in analyzing major sociological problems, although it is only recently that it has received more uptake in exploring diverse social relations. Brokerage has been a central point for enacting social, economic, and political transactions, especially when groups "monopolize goods or information and restrict access to outsiders" (Stovel and Shaw, 2012: 140) and "where a weak state cannot impose its own rationality" to a locale (McKay and Perez, 2019: 1906). When information is restricted and not well-distributed, opportunities for brokerage emerge. For example, 
property and migration brokers gain value for their work when they pull together crucial information from diverse sources for clients who have difficulty making sense of it by themselves (Lindquist, Xiang and Yeoh, 2012). By coordinating with multiple entities, brokers effectively transform information into practical knowledge that becomes marketable to clients. The brokerage process is also important in connecting isolated individuals or groups to "interact economically, politically, and socially" (Stovel and Shaw, 2012: 140).

The enactment of politics in the Philippines is underscored by brokerage. Brokerage works well within pervasive "patron-clientilistic relations" (Scott, 1972; Nowak and Snyder, 1974) where brokers obtain legitimacy to bridge ordinary constituents and political elites; in turn, the elites benefit from the brokerage by retaining their control over constituents (Nowak and Snyder, 1974: 23). Patronage structures are deeply embedded and have become a long-standing feature in Philippine society. Where politics is about mobilizing interests, persons able to influence and control the flow of information and resources set the agenda and attain power in shaping political outcomes. For example, politicians can appear distant from the masses and need political intermediaries who could intervene for them (Nowak and Snyder, 1974). Here, the brokerage function is based on an exchange - the broker promises resources, a political vision, or an illusion of closeness to the politician in exchange for a vote. Aspinall and colleagues (2016: 194) also emphasized the role of the 'liders' (campaign staff and vote brokers) in the contemporary Philippine political structure, whose in-person encounters with voters bring political candidates (and political aspirations) closer to the public through 'personalized patronage.' It is through personalized patronage that these brokers obtain influence by directly mobilizing people's interests and support, making them inconspicuous but crucial players in the political process. 
As the political economy became differentiated and with politics becoming more embedded in social media, specialized patron-client relationships have emerged in more functionally specific forms such as political machines and social media architects (Ong and Cabanes, 2018; Ong, Tapsell and Curato, 2019). However, the style and character of social media brokerage remain to be fully studied and unpacked along with the platform affordances that enable it.

\section{YouTube's affordances and platform governance mechanisms}

YouTube is no longer just a space for people's performance of everyday life, but as a platform where diverse social and political transactions are enacted, monetized, and brokered. Of late, YouTube's role in the information ecosystem has shifted from catering to lifestyle videos into hosting 'epistemic communities' where creators can make claims over knowledge and history (Utz and Wolfers, 2020). This development collides with participatory and do-it-yourself (D-I-Y) culture in social media, where creators share content with communities that then translate this knowledge into 'collective intelligence' (Jenkins, 2006). This D-I-Y culture of content creation departs from traditional expert cultures of knowledge creation and sharing underscored by gatekeepers and editors of content, bringing into fore new social imaginaries of YouTube as a platform. YouTube facilitates 'social learning' (Utz and Wolfers, 2020: 3) in a multimedia/infotainment format that makes information palatable. This is also supported by the evolution of YouTube into a 'hybrid cultural-commercial space' (Lobato, 2016: 357) where various forms of serious content become entangled with commercial or entertainment styles of presentation. Specific to brokerage, YouTube carries with it an inclusive, cultural characteristic that makes it a connective force not only between disparate forms of information, but also between disparate parties. 
Examining the working of YouTube requires identifying its material dimensions and how these interrelate with specific actors (i.e. brokers) and processes (i.e. brokerage) as a networked assemblage. The notion of an assemblage (agencement) consists of a "multiplicity of heterogenous objects, whose unity comes solely from the fact that these items function together, that they 'work' together as a functional entity" (Patton, 1994: 158). An assemblage works by virtue of its own characteristic set of operations that create physical and cognitive spaces and processes, and construct action (Deleuze and Guattari, 1987). This also implies that technological artifacts can be transformed into new configurations driven by local cultures of use (Rieder et al., 2018). Framing political brokerage on YouTube as an assemblage resurfaces the connectedness of communication systems with social systems, reflecting how technological features shape social relations, but also how social contexts shape technology. To examine brokerage on YouTube as a networked assemblage, it would be useful to look at the platform's governance mechanisms and affordances and how users appropriate these affordances.

YouTube's platform governance mechanisms and algorithms do things by embodying a 'command structure' (Gillespie, 2014) such that everyday experiences are mediated, augmented, and conditioned by the platform's affordances and logics. One key affordance is the facilitation of 'regimes of visibility' (Bucher, 2018), which are algorithmically modulating our capacity to achieve social attention or alternatively be rendered 'invisible' (Bucher, 2018). This algorithmic visibility is a crucial ingredient for brokerage to take place and can be understood as a part of 'aspirational labor' (Duffy, 2017: 9) of YouTubers whose careers depend on building social media presence and following. Connected to the notion of visibility is the process of 'ordering content' and the implicit rendering of relevance and legitimacy to certain actors (and their narratives) over others in the way they are sequenced in the search results and recommended videos 
(Gillespie, 2014). YouTube's 'ranking cultures' (Rieder et al., 2018) determines the level of value audiences give to them, with studies finding that while a broad range of content is made 'visible', attention is directed to the content that platforms privilege in terms of higher rank or order (Bucher, 2018).

These mechanisms of visibility and ordering are designed for platforms to 'curate' content for particular users. One way of curating content is through the categorization of users' preferences and consumption data through algorithmic processes. Considered to function as technological platforms' soft biopolitics and biopower, curating content to suit a user's tastes can be considered a political practice (Cheney-Lippold, 2011). Cohn (2019) argues, for example, that the creation of these personalized pathways to discovering content also expose a user to a curated narrative, and possibly, a narrower discourse. At the extreme level, research has associated platform curation work toward political polarization (Agosti et.al., 2018; Jamieson, 2018) and even radicalization (Conway, 2017), where users are 'precision targeted' by the platforms, pushing particular content to them based on their political inclinations, embedding them further in their political bubbles, and thereby relegating them as political subjects of the platforms. This personalization of content is highly connected to the brokerage process, especially as brokerage processes thrive in personalized affective narratives linked to people's personal aspirations, interests, and inclinations (Stovel and Shaw, 2012).

\section{Micro-influencers and brokerage on YouTube}

How platforms organize visibility and relevance of content for specific audiences configure the production of culture, economy, and politics and likewise affect the strategies and tactics of content producers. Yet, while they govern the circulation of content, it is the media creators that render the content attractive and valuable by making use of the platform's affordances (Burgess and Green, 2009) — visuals, sounds, narrative 
styles, self-recommendations, comment features, among others. This enables the rise of 'ordinary experts' (Utz and Wolfers, 2020: 3), or amateurs who pull together diverse informational content and blend information, interpretation, and entertainment in their videos and channels through instructional formats like explainer videos to present themselves as experts.

YouTube and influencer relations literature abounds (Marwick, 2015), but the relationship between micro-influencers and political interlocution has been explored with more depth only more recently through the analysis of alternative influence networks (Lewis, 2019). Examination of YouTube influencers' political role also often do not fully examine how influencers bridge national, economic, and political aspirations, especially in the context of the Global South. Online micro-influencers pertain to social media users with niche audiences and followings who employ creative strategies adopted from traditional celebrity culture to maintain attention and cultivate and maintain those audiences (Lewis, 2019; Marwick, 2015; Abidin, 2017, 2015).

The concept of microcelebrity and social media influencers is largely understood in niche-like environments such as fashion, entertainment, travel and the like, and often in the context of affluent societies. Similarly, the operation of brokers has often been studied in the context of more traditional face-to-face engagements. The relationship between social media micro-influencers and political brokerage is not well-established, but we can see multiple intersections in their strategies and how their work attracts value. We can see political brokers' role as bringing together dispersed information into knowledge which they then use to build monetizable social transactions with their publics. The broker can intermediate between a politician and the public, and the public supports candidates and their narratives by triggering political aspirations translated with personal relevance, and through articulation by 'ordinary expertise' that render them more 
believable. So does a micro-influencer, crafting and maintaining 'communicative intimacies' (Abidin, 2015) to maintain loyal audiences by effectively selling a lifestyle deemed of value to their target publics by satiating specific aspirations.

As we discuss in later sections, brokers, like micro-influencers, are conscious of the platform's vernaculars and employ corresponding presentation and engagement tactics that crystallize their brokerage role. When influencers have established an 'expertise', they can build on this persona by maintaining and targeting the communication to initial subscribers, affectionately referring to them as part of his or her community (Marwick, 2015; Abidin, 2015, 2017) and with the constant intention of growing this community to facilitate a more organic exchange of content and maintenance of income stream. With the creation of previously unavailable linkages, enacting a community through the engagement of multiple social media affordances illustrates the tight relationship between microcelebrity and brokerage in this contemporary digital environment.

\section{Methodology}

Platforms' ubiquity in social life renders it familiar and almost intuitive, but in reality, its workings remain obscure and hidden from view (Gillespie, 2014). What is accessible and observable is their algorithmic output that shapes the transactions and relations possible and permitted in the platform. While these are a product of its computational logics, it is only through its interaction with users, content creators and other social actors that these logics become meaningful and apparent (Bucher, 2018). This study $^{3}$ adapts Taina Bucher's (2018) methodological approach of technography, which repurposes ethnographic methods to study the intersection of software and sociality to

\footnotetext{
${ }^{3}$ The study was subjected to review and approval of the concerned University Ethics Board.
} 
materialize the platforms' underlying assumptions and interests. We surface the ways YouTube as a networked assemblage facilitates the production of historical revisionist narratives by looking at the products of the social relations between users, brokers and the platform in the form of search results, recommendations and content. It is not completely knowable how platforms work, and our interrogation of YouTube is only partial and is subject to change (Bucher, 2018).

Data were collected by 'following the medium' (Rogers, 2013) and using the 'native' logics of YouTube of searching, viewing and being fed recommendations to construct the assemblage of YouTube videos and brokers connected to political historical revisionism. Using a clean, cookie-free browser, we reproduced users' search behavior using the keywords "Marcos history as the top YouTube query of 'rising' search frequency related to "Ferdinand Marcos" from October 2015 (when Marcos' son filed for candidacy for vice presidency) to March 2020, derived from the tool Google Trends (Image 1). We documented the top 10 videos and their respective rankings and proceeded to watch the top videos produced by those we consider brokers, or informal and amateur content creators unaffiliated with institutional or professional groups. After watching each video in full, we recorded the top 10 suggested videos appearing in the 'Up Next' column. This process was conducted thrice within a week by two separate researchers, yielding 600 videos, with a number of them suggested multiple times. 


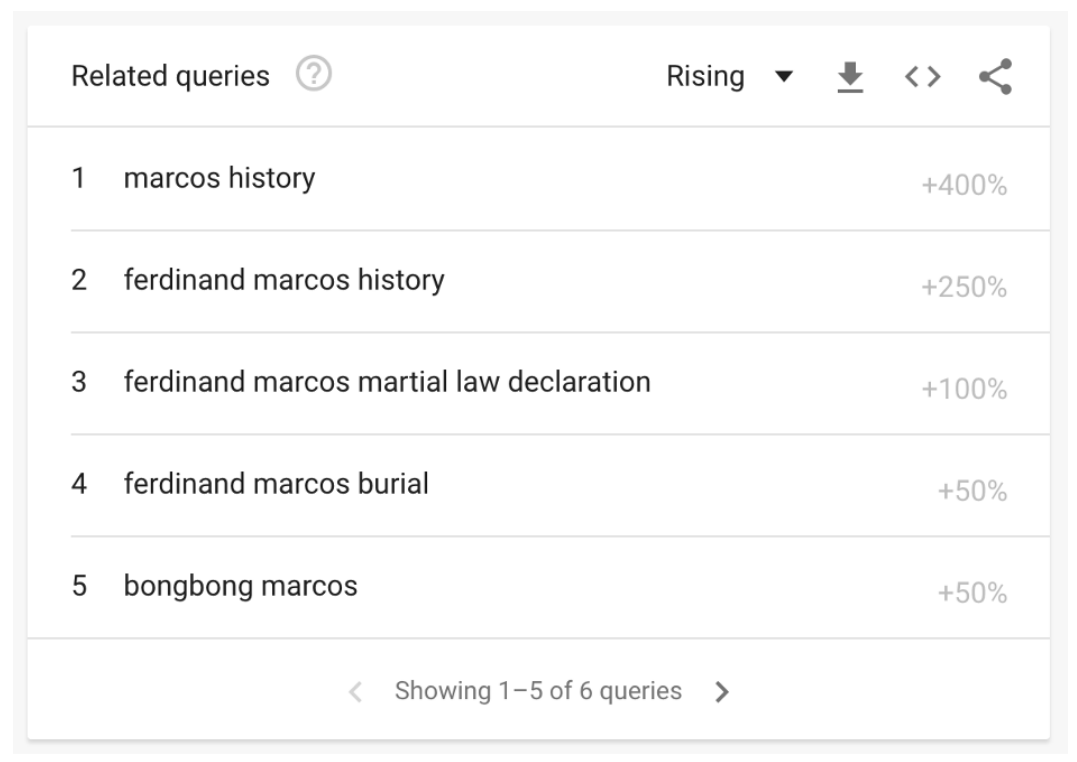

Image 1. YouTube 'rising' related queries to the keywords 'Ferdinand Marcos' in Google Trends from October 2015 to March 2020

From those brokers appearing in the search results, we examined the videos and the brokers' channels using textual analysis and classified them according to their emergent content categories (e.g., 'educational', campaign, conspiracy; see findings for all categories). We also identified if videos incorporated disinformation (presentation of false historical information as fact), distortion (misinterpretation or misrepresentation of facts, data and accounts of events) or fabrication (construction of fictional, mythical or conspiratorial narratives) of known facts about the Marcos era and related events using multiple historical, institutional and media sources as reference (Mijares, 1976; Seagrave, 1988; Official Gazette, 2015), thereby qualifying as historical revisionism (Bautista, 2018; Aguilar, 2019). Finally, we performed a close reading of the specific strategies they used to attain visibility on YouTube and appeal to audiences, paying attention to their cultures of use (Rieder et al., 2018) of platform affordances, algorithmic logics and viewer engagement strategies. 
Using the data visualization tool Gephi, we transformed the YouTube video list into a video recommendation network using social network analysis, which is the technique of examining social relations as a network composed of nodes (in this case, YouTube brokers) and edges (links between the brokers created through the suggested video list) (Caliandro and Gandini, 2017). We created a social network graph for each iteration, with the second and third iteration drawing from data from the earlier iterations. The YouTube recommendation network was analyzed to identify the relations among videos and brokers that appeared in the search results and the algorithmic recommendations, as well as to characterize how users might experience the brokerage process in the sequence the videos are presented in the platform.

\section{Political brokerage on YouTube}

\section{YouTube's logics of brokerage}

YouTube works as a socio-technical broker through the complex connections it creates not only between users and brokers, but also between political brokers. These distinct data-driven relations construct an 'assemblage of networked brokerage', wherein individual brokers wield credibility and capital from the network to advance political interests. We illustrate it through the lens of the platforms' native logics and the ways that YouTube enable, favor and perpetuate the political narratives of pro-Marcos microinfluencers.

For the keywords 'Marcos History', YouTube presents slightly varied search results and video rankings in each iteration and between the two researchers (R1 and R2, respectively), but recurring brokers appear in the top 10 (Table 1). Eight out of the top ten search results are 'amateur' video creators, while the other two channels are affiliated with 'professional' organizations. Sangkay Janjan TV, a channel with 468,000 subscribers as of October 2020 and a prolific pro-Marcos YouTuber, consistently takes 
the first spot in the search results. His top video was about the Philippines purportedly becoming a global superpower if Marcos stayed in power, claiming that economic and social downturn only began after Marcos' time, which substantial documentary evidence disputes (Mandrilla and Punongbayan, 2016). The only historical institution appearing in the top 10 is Martial Law Chronicles (ML Chronicles), a civic group against historical revisionism. The rest of the micro-influencers are identified to promote revisionist narratives and propaganda presented as historical or educational content, containing distortions on Marcos' economic achievements, ill-gotten wealth, and human-rights violations (Official Gazette, 2015).

Table 1. Broker cumulative search ranking

\begin{tabular}{|c|c|c|c|c|c|}
\hline Brokers & $\begin{array}{c}\text { Subscriber } \\
s\end{array}$ & Featured video & $\begin{array}{l}\text { Video } \\
\text { views }\end{array}$ & $\begin{array}{c}\text { Rl } \\
\text { ranking }\end{array}$ & $\begin{array}{c}R 2 \\
\text { ranking }\end{array}$ \\
\hline $\begin{array}{l}\text { Sangkay } \\
\text { Janjan TV }\end{array}$ & $306 \mathrm{~K}$ & $\begin{array}{c}\text { IF MARCOS' PLANS } \\
\text { PUSHED THROUGH, } \\
\text { THE PHILIPPINES } \\
\text { WOULD BE BETTER } \\
\text { THAN THE US (trans.) }\end{array}$ & $1.6 \mathrm{M}$ & $1 \mathrm{st}$ & $1 \mathrm{st}$ \\
\hline $\begin{array}{c}\text { ML } \\
\text { Chronicles }\end{array}$ & 2670 & $\begin{array}{c}\text { BATAS MILITAR: } \\
\text { Martial Law Under } \\
\text { President Ferdinand E. } \\
\text { Marcos Full } \\
\text { Documentary }\end{array}$ & $486 \mathrm{~K}$ & 2nd & 2nd \\
\hline OHJAYCEE & $11.3 \mathrm{~K}$ & Ferdinand Marcos' last & $860 \mathrm{~K}$ & $3 r d$ & $3 r d$ \\
\hline
\end{tabular}




\begin{tabular}{|c|c|c|c|c|c|}
\hline & & words (trans.) & & & \\
\hline pincus 1974 & 284 & $\begin{array}{c}\text { Aquino Cojuangco } \\
\text { FACTS THEY DONT } \\
\text { WANT YOU TO KNOW }\end{array}$ & $331 \mathrm{~K}$ & 4 th & 4 th \\
\hline $\begin{array}{c}\text { News5Every } \\
\text { where }\end{array}$ & $1.9 \mathrm{M}$ & $\begin{array}{c}\text { Martial Law Myths } \\
\text { Busted | History }\end{array}$ & $196 K$ & 5 th & 10th \\
\hline Jevara PH & $2.8 \mathrm{~K}$ & $\begin{array}{c}\text { The great } \\
\text { accomplishments of } \\
\text { Ferdinand Marcos } \\
\text { (trans.) }\end{array}$ & $448 \mathrm{~K}$ & $>10$ th & 5 th \\
\hline JD Bros & $111 \mathrm{~K}$ & $\begin{array}{c}\text { THE HISTORICAL } \\
\text { INTERVIEW OF } \\
\text { FERDINAND MARCOS } \\
\text { AND CORY AQUINO } \\
\text { BEFORE THE } 1986 \\
\text { ELECTIONS }\end{array}$ & $267 \mathrm{~K}$ & 6 th & 7th \\
\hline Tinig PH & $143 \mathrm{~K}$ & $\begin{array}{l}\text { "Did you know?" How } \\
\text { the Philippine presidents } \\
\text { died (trans.) }\end{array}$ & $358 \mathrm{~K}$ & $>10$ th & 6 th \\
\hline $\begin{array}{l}\text { Paolo } \\
\text { Araneta }\end{array}$ & 4780 & $\begin{array}{l}\text { Philippine most } \\
\text { intelligent President } \\
\text { Ferdinand Marcos }\end{array}$ & $1.6 \mathrm{M}$ & 7 th & $>10$ th \\
\hline
\end{tabular}




\begin{tabular}{|c|c|c|c|c|c|}
\hline & & (September 17, 1982) & & & \\
\hline Epimetheus & $299 K$ & $\begin{array}{l}\text { Was Ferdinand Marcos a } \\
\text { Villain or Hero? (History } \\
\text { of the Philippines, } \\
\text { Marcos Biography }\end{array}$ & $248 \mathrm{~K}$ & 8th & $>10$ th \\
\hline $\begin{array}{l}\text { Mr. Riyoh } \\
\text { Channel }\end{array}$ & $137 \mathrm{~K}$ & $\begin{array}{c}\text { Real talk about } \\
\text { MARCOS - Mr. Riyoh }\end{array}$ & $683 \mathrm{~K}$ & $>10$ th & 8 th \\
\hline $\begin{array}{c}\text { Arthur James } \\
\text { Frayalde } \\
\text { Tagaban }\end{array}$ & 1660 & $\begin{array}{c}\text { Marcos: The Hidden } \\
\text { Truth }\end{array}$ & $405 \mathrm{~K}$ & 9th & $>10$ th \\
\hline MAKITYAN & $5.7 \mathrm{~K}$ & $\begin{array}{l}\text { THE STORY BEHIND } \\
\text { THE MARCOS } \\
\text { WEALTH (tallano } \\
\text { family) (trans.) }\end{array}$ & $215 \mathrm{~K}$ & $>10$ th & 9th \\
\hline $\begin{array}{c}\text { Mark } \\
\text { Anthony } \\
\text { Domen }\end{array}$ & 1910 & $\begin{array}{c}\text { Marcos Life: The Untold } \\
\text { Story }\end{array}$ & 3779 & 10th & $>10$ th \\
\hline
\end{tabular}

In each of the videos we watched, YouTube generates a list of suggested videos that it recommends the viewers to see next and the emergent recommendation networks are visualized in Figures 1 and 2. The major nodes represent the brokers who produced the videos listed in search results, and the edges or lines connect them to the minor nodes, 
which stand for the brokers whose videos appear in the suggested video list. The thicker the edge between one broker to another, the more frequent they are recommended and the higher their rankings are in the list.

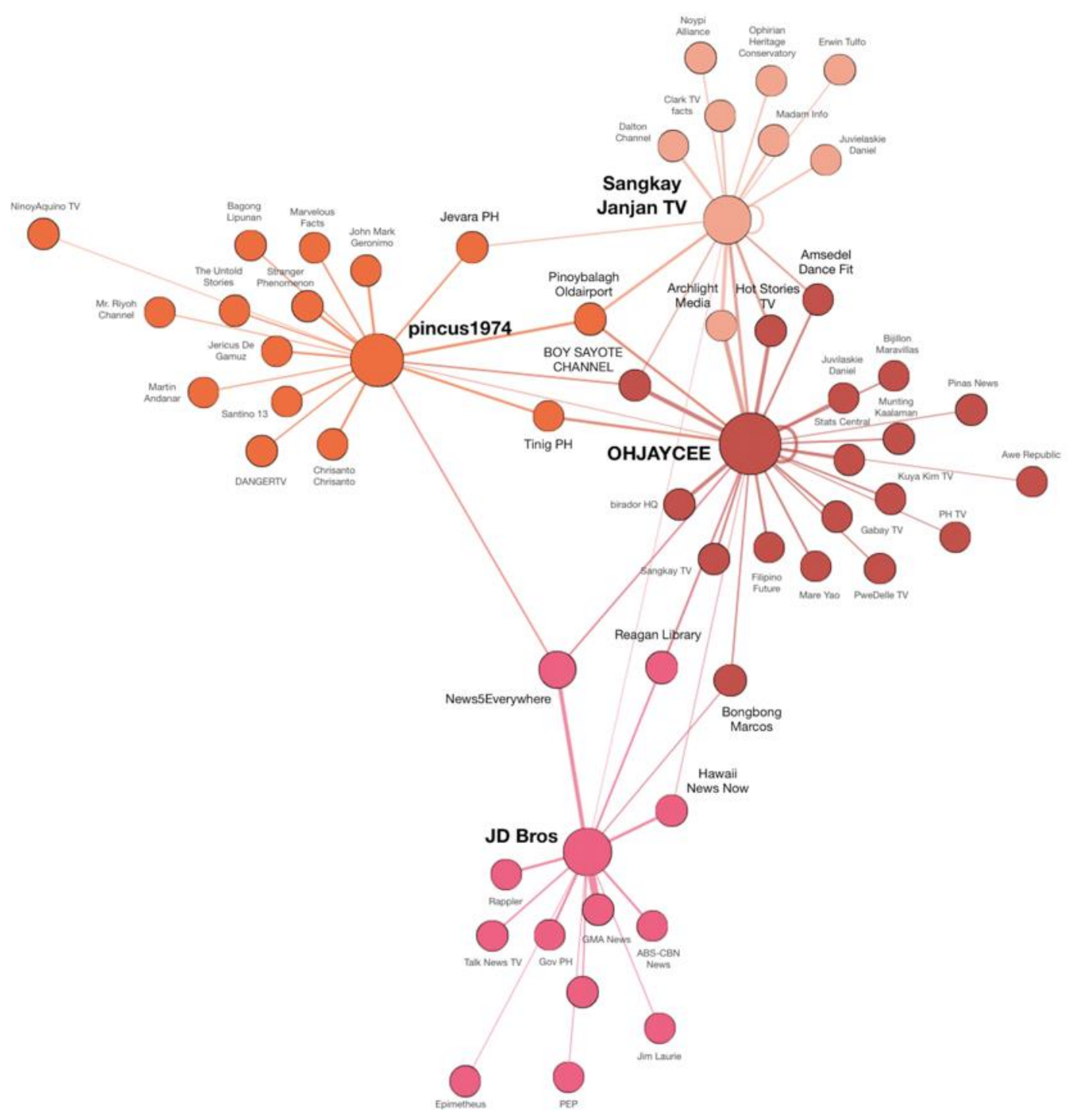

Figure 1. YouTube recommendation network for R1 first iteration 


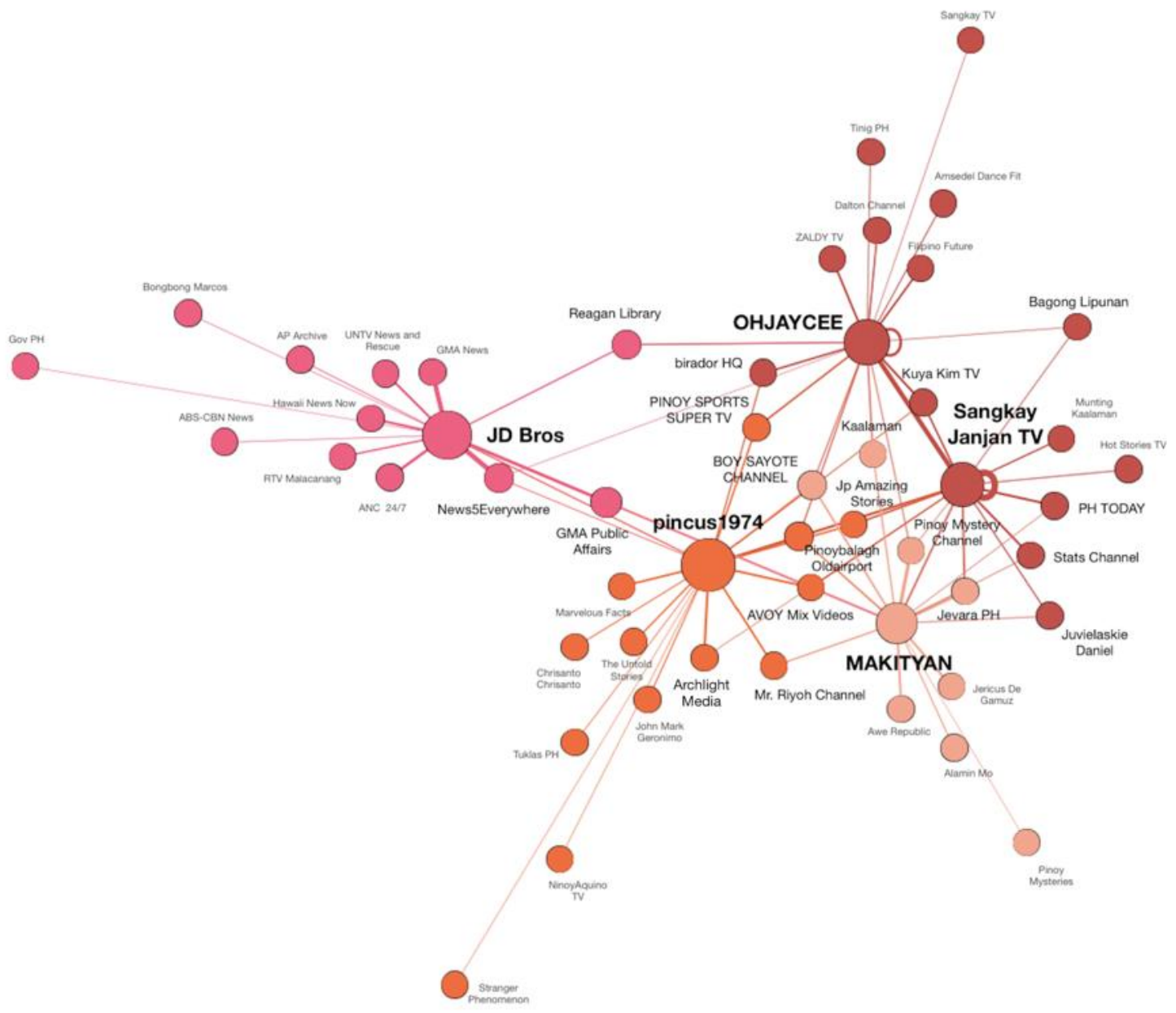

Figure 2. YouTube recommendation network for R2 first iteration

In general, the top recommendation is from the same micro-influencers of the video originally viewed on a related topic, as illustrated by the loop around a number of key brokers (Figure 3a). Videos of Sangkay Janjan $T V$ were recommended for a total of six times after viewing his first video, while OHJAYCEE received four suggested videos from its channel. About 20 percent of the brokers of the suggested videos were interlinked through the platform's algorithmic recommendations, indicating their videos were suggested more than once (Figure $3 \mathrm{~b}$ ). The interconnected minor nodes include brokers who present themselves through their visual and discursive strategies as 'educational' channels (Image 2) promoting Marcos propaganda (Jevara PH, Tinig PH, Gabay TV), 
attack channels against the opposition (Pinoybalagh Oldairport, birador HQ, Mr. Riyoh Channel), and folklore and conspiracy channels (Hot Stories TV, Boy Sayote Channel, Awe Republic, etc.). There are also overlapping nodes of official campaign channels of Ferdinand Marcos' son and politician, 'Bongbong' Marcos (Bongbong Marcos, Bagong Lipunan), as well as several news and institutional sources (News5Everywhere, Reagan Library, GMA Public Affairs). However, most of the news and reputable organizations are only clustered around one major node (JD Bros), which reposted media footages of international TV interviews of former presidents Ferdinand Marcos and Cory Aquino.

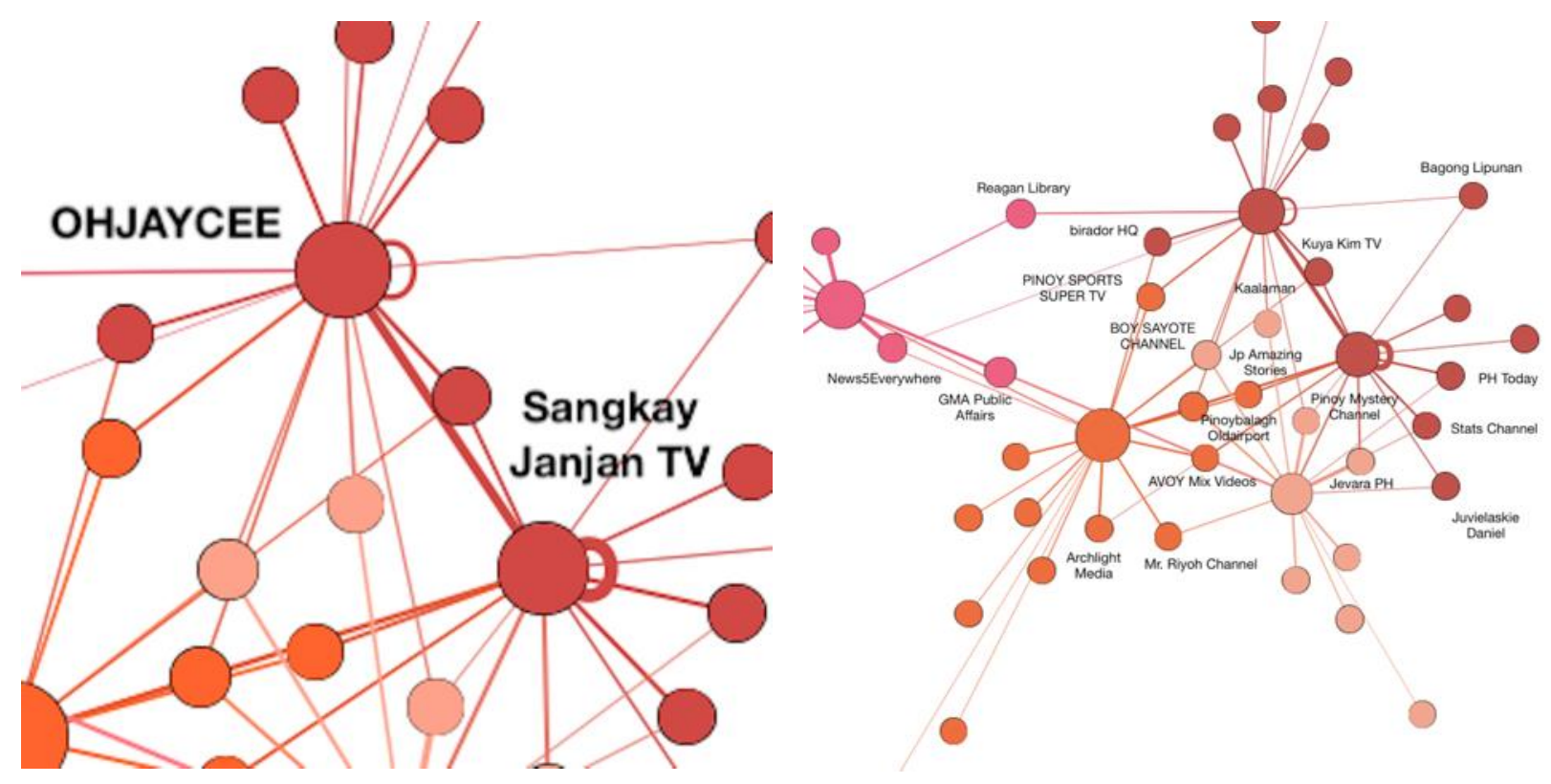

Figure 3. (a) R2 Subgraph showing loops around major nodes to represent YouTube recommending videos from the same micro-influencer; (b) R2 Subgraph that illustrates interconnected minor nodes, broadly categorized as 'educational' propaganda channels, opposition attack channels, and folklore and conspiracy channels. 


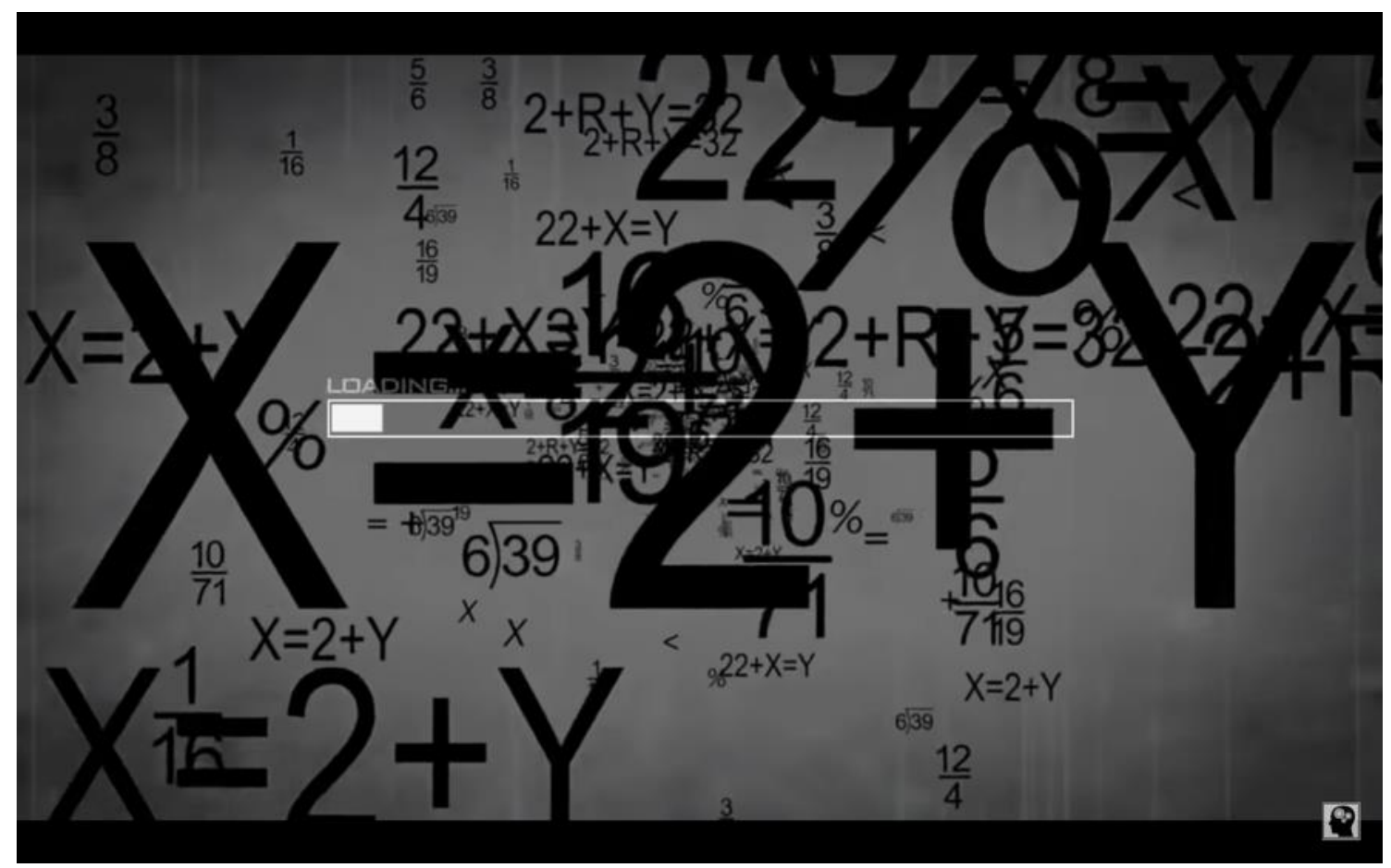

Image 2. Jevara $P H$ packages itself with imagery related to knowledge and facts in order to present the channel as 'educational.'

In the second and third iteration, up to $80 \%$ of the brokers were recommended again, which suggests that they are deeply entangled in the web of algorithmic connections in the pro-Marcos brokerage network (Figures 4 and 5 for R1; Figures 6 and 7 for R2). The Gephi algorithm has also clustered the major nodes together (marked by the same colored nodes), which signals the high-density connections between their recommended micro-influencers, such as that of Sangkay Janjan TV and Mark Anthony Domen (Figure 8a). Official campaign channels (Bagong Lipunan, Filipino Future), including Bongbong Marcos (channel of the son of the late President) have become increasingly connected to the network, increasing their connections for up to four nodes (Figure 8b). There are also more linkages between the minor nodes for up to seven connections, especially for 'educational' channels, attack channels, and folklore and conspiracy channels. In both succeeding iterations, JD Bros and pincus 1974, channels 
that only reposted media reports and documentaries, remain relatively distant from the rest of brokers that produced original YouTube content. The media and reputable channels also maintain their separation from the denser part of the network.

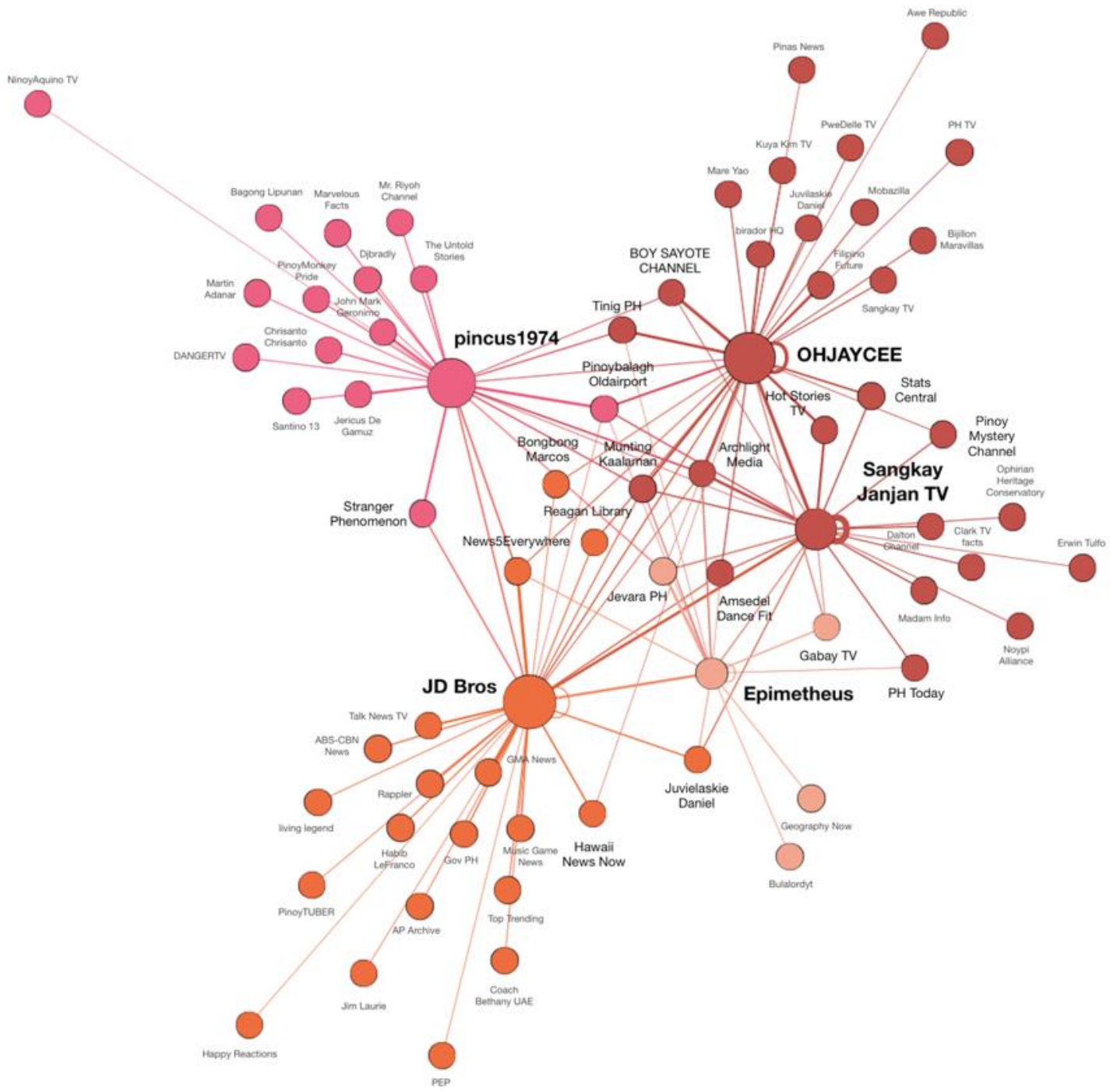

Figure 4. YouTube recommendation network for R1 second iteration 


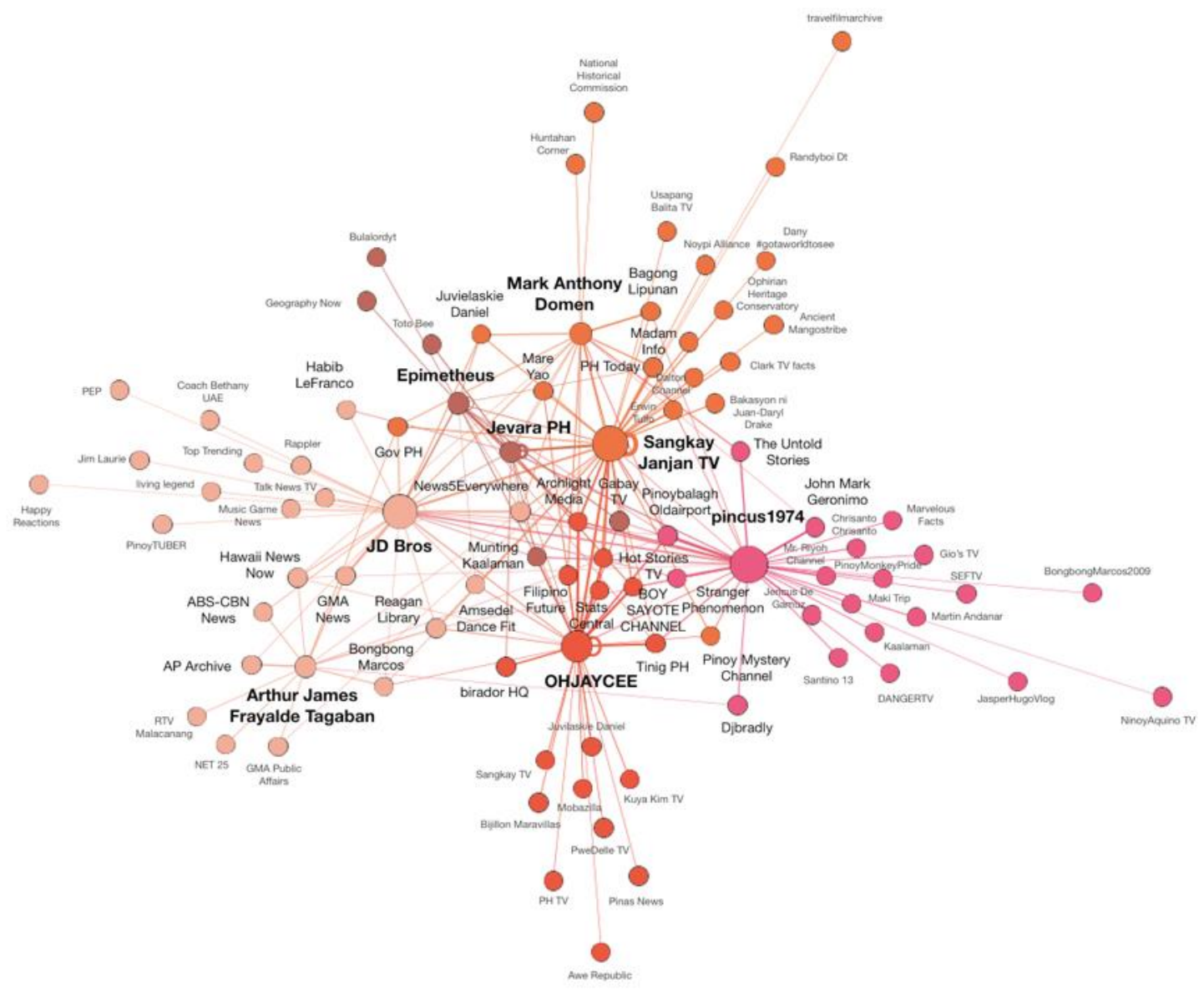

Figure 5. YouTube recommendation network for R1 third iteration 


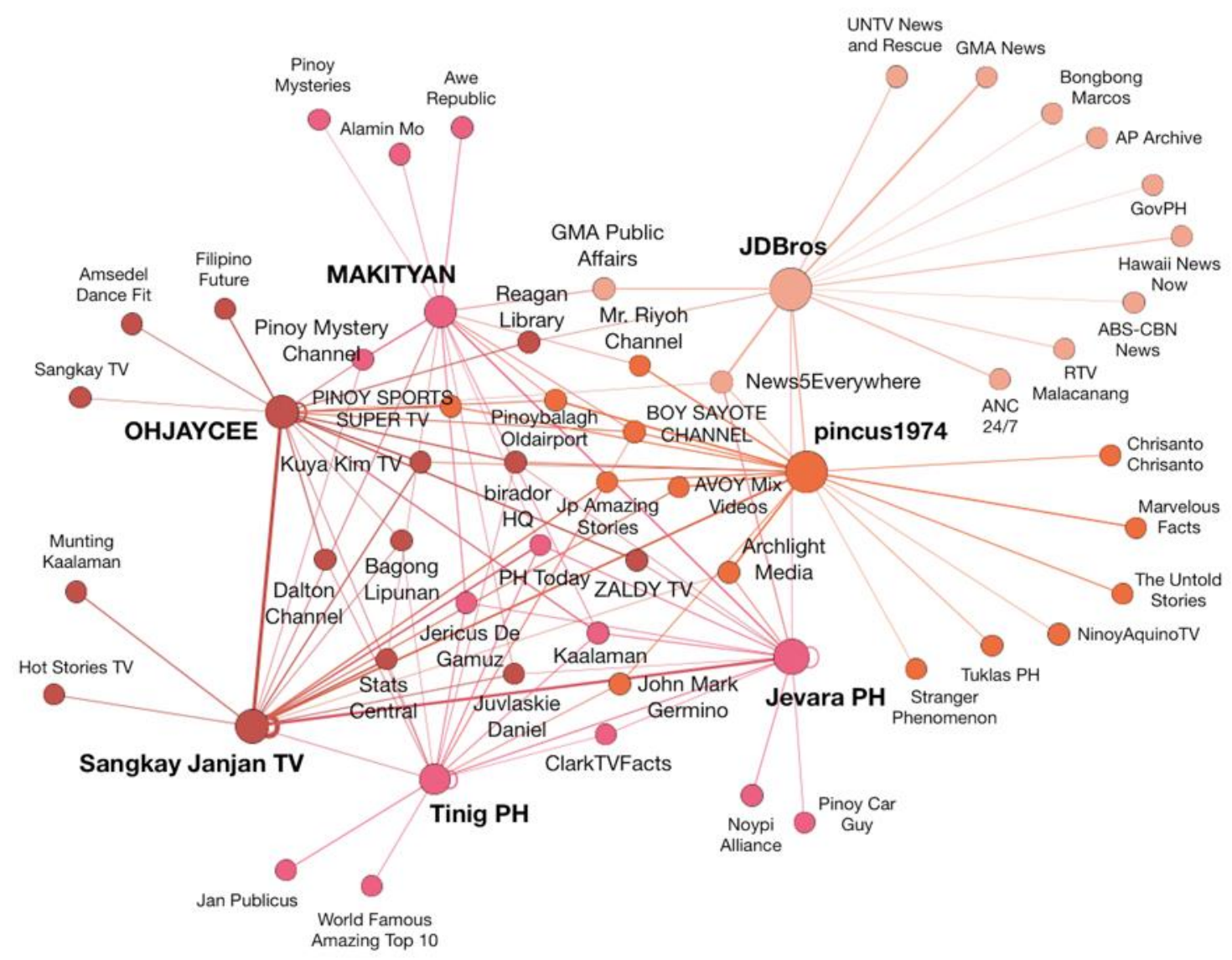

Figure 6. YouTube recommendation network for R2 second iteration 


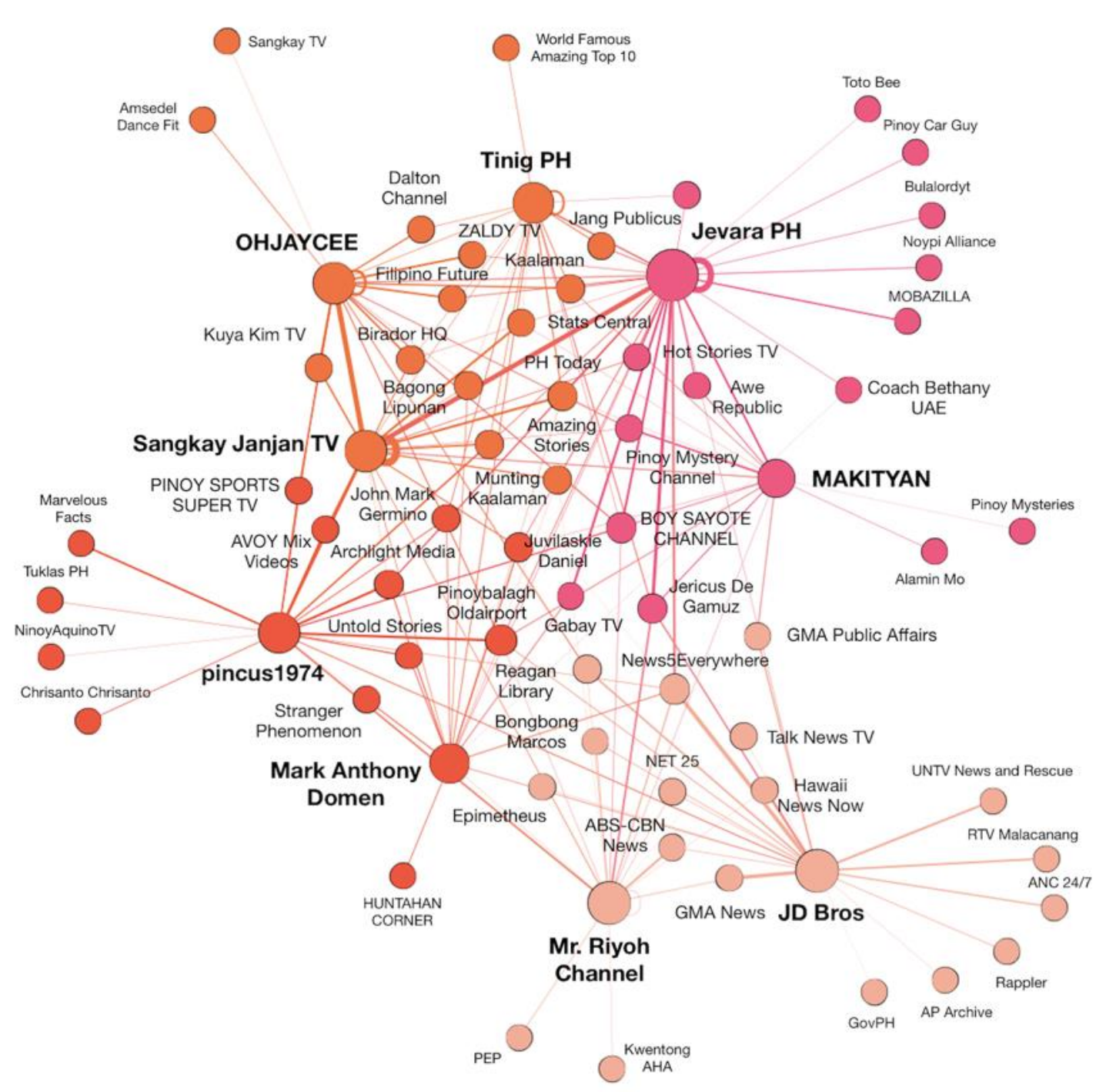

Figure 7. YouTube recommendation network for R2 third iteration 


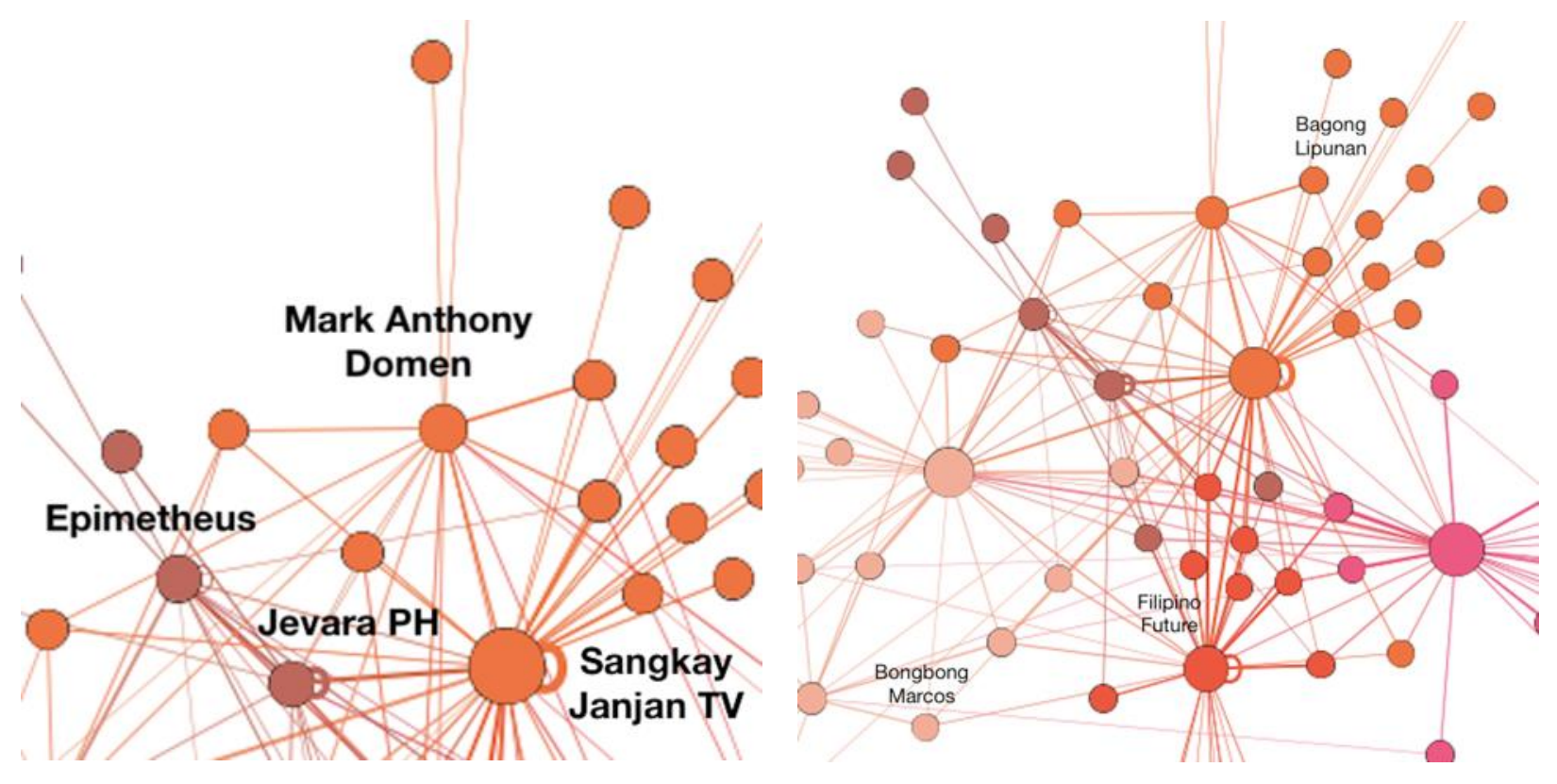

Figure 8: (a) R1 Subgraph of new clusters of major brokers produced by the Gephi algorithm indicate the high-density connection between their sets of suggested videos; (b) R1 Subgraph of campaign channels of Bongbong Marcos that have increased their connectedness in the network relative to their isolated positions in the first iteration.

\section{Broker strategies}

The political brokers on YouTube advancing Marcos propaganda negotiate their visibility and relevance not only with the platform, but also with the users whose consumption behavior are translated into data that feeds into YouTube's bottom line. Their intricate knowledge of the platform and its interest in generating millions of 'watch time' manifest in how they leverage its affordances through the use of logical and affective strategies. Some of these tactics are apparent in the platform's interface, while the others are hidden underneath layers of code discoverable only through deliberate probing.

Logical tactics pertain to the micro-influencers' strategies of attuning their YouTube presence and performance to its affordances of visibility, ordering, and 
curation. The most apparent of these tactics is the strategic use of keywords in the video title to signal the platform and the viewers of the videos' relevance to the search terms. Apart from the videos containing variations of the search keywords 'Marcos' and 'History' in their titles, they also included keywords that were semantically close ('facts', 'myths', 'kwento' or story) and discursively related ('Cory Aquino', 'Elections', 'Kayamanan ni Marcos' or Marcos' wealth), to tap into parallel searches using these keywords. A number of video titles suggest the existence of concealed or undisclosed historical accounts through the use of expressions such as 'Untold History' and 'Hidden Truth'. Other title keywords with claims like "The Philippines would be better than the US (trans.)" and "...would be great again (trans.)" (if Marcos stayed in power) present users with grand economic and political ambitions for the country. These phrases are common click-bait headline tactics in social media, but it can also work to interpellate viewers into subjects who are receptive to historical revisionism, disinformation, and aspirational narratives, more broadly.

Behind the YouTube interface are keyword tags attached to each video. These tags are only viewable through the page source, which contains the code for the web page. The micro-influencers use the tag function generously to expand the topics their videos can be associated with. Apart from the keywords related to the search term, Sangkay Janjan $T V$ also included names of prominent political personalities ('Ninoy Aquino', 'Cory Aquino', 'President Duterte') and tagged local YouTubers ('Jamill', 'Cong TV', 'Wil Dasovich') with millions of subscribers, potentially to ride on their popularity. Jevara PH notably uses search phrases in his video tags: "The great accomplishments of Ferdinand Marcos (trans.)", "The things you don't know about Marcos (trans.)", and "Is it true that it was the [Philippines'] golden age during Marcos' time (trans.)." This also manifests in the tags used by OHJAYCEE related to other myths about the late dictator ('marcos gold', 
'taliano gold' and 'yamashita treasure'). In contrast with the brokers above, ML Chronicles, the only civic historical organization on the list, only used straightforward keywords like 'martial law' and the names of Marcos and his children involved in politics.

The micro-influencers also used the affordance of assigning their channels and videos to categories as another way to inform the platform how to classify and group them in its database. While the search terms are related to history, the channels of the brokers do not necessarily fall under the 'history' and 'education' categories of YouTube. Jevara $P H$ was the only major broker that identified its channel and video under the education category. The rest of the major brokers labelled their channels under the general categories of people and blogs, entertainment, and news, but these categories do not always reflect the kinds of videos they create. In its cover photo, OHJAYCEE highlights the range of topics featured in its videos (Image 3) apart from entertainment content. Both JD Bros and Arthur James Frayalde Tagaban, whose channels are categorized as comedy and music respectively, identified their videos of Marcos giving speeches as 'News'. This tactic by the micro-influencers of casting a wide net in the ways they identify the categories of their channels and videos may be a way to make them appeal to broader interests of YouTube audiences and generate more views for their videos.

[Insert Image 3.]

Affective tactics are the micro-influencers' ways of employing branding, engagement and community-building strategies to build credibility and affinity among their YouTube audiences. Apart from viewership, YouTube factors in interactions in its calculus of prioritizing videos in its rankings and the brokers embed various engagement tactics in their content (Cooper, 2020). All micro-influencers who create original content actively and constantly call the attention of their viewers to comment, like and share the videos through 'shoutouts' and recommend topics for their next videos under the 
comment section. They also engage in more overt strategies by seeking help from viewers to reach their engagement target, explicitly calling viewers to "help this video reach 500 likes!" (Birador HQ, 2020) or inviting them into a debate in the comments section if "Marcos [was] a villain or a hero" (Epimetheus, 2018).

The micro-influencers elevate the one-off engagement with the users by inviting them to subscribe and be notified ("Press the bell button") of updates in the videos, as well as to see other videos they produced. These platform affordances are complemented by the micro-influencers' tactics to build affinity and intimacy with the viewers - similar with the strategies of traditional brokers - by using local terms referring to a collective unit, such as 'mga ka-sangkay', a Visayan term pertaining to a circle of close friends and 'mga birador', addressing a community of sharp shooters with a clear (political) target. Affective language is also prominently used, for example, "To our loyal subscribers in our channel, long live! (trans.)" (Sangkay Janjan TV, 2019). Generally, they invoke patriotic and nationalistic feelings when they talk about Marcos and those who support his family to reinforce their moral ascendancy, while employing crass and vulgar language to disparage anti-Marcos personalities and individuals.

\section{The assemblage of networked political brokerage}

YouTube's affordances and logics, and its cultures of use among a genre of political actors, shape contemporary political brokerage in three critical ways. First, it builds connections and visibilizes a network of disparate traditional and emergent political actors in an overabundant social field. Secondly, it constructs and legitimizes a network of political narratives, not only from dispersed and inaccessible historical accounts, but also from coordinated fabrications and distortions. Lastly, these networks of brokers and their narratives work together to manufacture 'sensibility' (Bucher, 2018) 
and intimacy between political actors and users that strengthen the resonance of Marcos' historical revisionist accounts to the Filipino public. We discuss in detail the transformative influence of this assemblage of networked political brokerage in terms of the following: visibility, ordering, categorization, and curation.

\section{Visibility}

Bucher (2018) argues that platform logics do not necessarily dictate which becomes visible or not; rather, it sets 'new conditions' through which visibility is constructed. These conditions constitute the platform's regimes of visibility and they are capitalized by the pro-Marcos brokers for YouTube to grant them visibility, and in extension, privilege their political narratives. They achieve this by delivering millions of views, engagement and subscriptions, which are the currency of YouTube's business model. The micro-influencers also engage in strategies that make them 'algorithmically recognizable' (Gillespie, 2017), such as using keywords and tags to respond to present and future search demands, positioning themselves in spaces of interest through categorization, and sustaining viewer attention by drawing from micro-celebrity engagement tactics. The ability of the brokers to embody and practice the platform vernaculars (Rieder et al., 2017) allows them to dominate in the discursive space of 'history' without the credentials nor the scrutiny of traditional gatekeepers and advance their version of history as a compelling political narrative. YouTube functions as a political device that renders particular forms of discourses as 'sensible', which sets the "horizons and modalities of what is visible and audible as well as what can be said, thought, made, or done" (Ranciere in Bucher, 2018: 68). By making pro-Marcos political narratives visible, YouTube participates in normalizing them and undermining those that oppose or conflict their accounts, regardless of the factuality or accuracy of their content. Further, the circular logic of algorithms sustains the prominence of these narratives. 
Microcelebrities that adhere to YouTube's regimes of visibility are more likely to appear in the platform, which gives them higher chances to be granted further visibility in the future.

\section{Ordering}

Closely related to visibility is the platform's ordering and organizing of content which effectively demarcates which narratives are deemed more relevant than others. This ranking culture builds on practices in search engine optimization, where 'quality' can be manufactured by accumulating the appropriate keywords, volume of views, and strategic 'backlinks' or connections with other channels (Muller, 2020). In the case of pro-Marcos brokers, YouTube creates linkages between videos, channels and topics by relying on the micro-influencers' self-reported relations to those topics and other brokers. They can be affiliating themselves with those within the same political discourse, those that "thrive on controversy and dissent" (Rieder et al, 2018: 64) such as the folklore and conspiracy channels, and even those unrelated or only tangentially associated for as long as they are popular on the platform. Traditional brokers fulfill the same role of matching diffused and distant actors and information (Stovel and Shaw, 2012), except that YouTube does not evaluate the factuality and accuracy of these micro-influencers and their narratives, nor does it have clear-cut moderation policy on content that might contain disinformation (Gillespie, 2018). Only in cases when there is a public backlash does YouTube put in place oversight and overriding algorithmic mechanisms, such as in the case of vaccine-related information (Rieder et al, 2018). Micro-influencers accumulates this social capital and exploit power law in social networks (Barbási, 2003), or the exponential returns of ranking high in the network. Consistently positioning pro-Marcos brokers as the top videos in its search results over civic or historical institutional references under the search word 'Marcos history' indicates its endorsement of the micro- 
influencers and the political narrative they promote. The high rank of these political brokers over trusted and vetted sources of historical knowledge lend it proxy markers of authority.

\section{Categorization}

Categorization is a 'political intervention' through the use of semantics that defines the boundaries and designates meanings in the social world (Gillespie, 2014). There are two ways categories work for the pro-Marcos brokers: first, as a basis for YouTube in organizing them with the rest of its video database, and second, as a way to help viewers in evaluating the brokers and their video. YouTube's affordance of assigning categories to videos and channels separately allows for the brokers to place itself within a wide range of categories, such as those relevant to the search keywords (Marcos, history, politics, etc.), those related to other brokers' political discourse (talking points, counter-narratives, myths, etc.), and those that appeal to broader audiences ('educational', 'news', 'entertainment'). In effect, YouTube enforces these categories at the same time that it obfuscates them, particularly in a cultural milieu where categories like 'news' are made ambiguous by participatory culture (Madden, Lenhart and Fontaine, 2018), as well as in

a Philippine context where politics is intertwined with entertainment, and vice versa (Pertierra, 2016). For viewers, the categories with which the micro-influencers' group themselves and their narratives serve to justify their content as 'knowledge' and not propaganda, as 'hidden history' not disinformation, and as 'counterculture' and not as establishment with vested political interests, which effectively let them evade questioning and criticism. The greyness in the ways brokers perform political interlocution enables them to move between these categories, depending on which advances their political agenda. The viewers' political inclinations also factor in how the brokers' content is 
assessed, and categories work as paratext that can reinforce confirmation bias from the exposure to the supporting 'evidence.'

\section{Curation}

Finally, YouTube facilitates political brokerage through its capacity to curate and personalize political information and experiences. As a new kind of socio-technical broker, not only is it involved in the exchange of values between parties but also in the cultivation of values through the recurring and selective exposure of viewers to particular sets of brokers. This engenders networked brokerage, with the brokers building on, complementing, or magnifying their political narratives through and within the network of algorithmically-sanctioned videos. The process of curation and personalization begins with the assumptions that the platform makes about the users' interests and preferences, which materializes as their 'algorithmic identity' (Cheney-Lippold, 2017: 165). However, YouTube is less concerned about the 'user' but the "decomposition and recomposition of the data the users provide" (Bucher, 2018: 85). These data points do not necessarily represent the users nor them as political subjects, but as ideal customers who are fed content based on their capability to consume. In other words, political messaging is delivered following marketing logics by recommending the brokers and videos that would keep viewers watching, while constantly collecting more data about what the users watch, whom they engaged with, and to which channels they subscribed to. As such, YouTube not only amplifies the brokers and their messages, but reinforces their content by curating them as a network, illustrated by the clustering of nodes in the recommendation network graphs. News and traditional gatekeepers being isolated from the main network lessen their chances of being seen and are rendered 'peripheral' to the discursive space of history related to Marcos. The consequence is the experience of a narrower political discourse, where users are exposed to a set of politically-aligned brokers who mutually support and 
fortify each others' narratives, in the guise of free and diverse choices (Cohn, 2019). Brokers take advantage of this manufactured proximity by building intimacy with users through specific kinds of affective engagement and communication, which creates datadriven parasocial relations between them and their viewers. As such, the brokers eliminate the social distance between them and users, as well as facilitate cohesion in the gaps in information and knowledge in the broader political structure (Stovel and Shaw, 2012).

\section{Conclusion}

This study has examined YouTube as a socio-technical actor facilitating the construction of political and historical discourses through an assemblage of actors forming a 'networked political brokerage'. We showed that networked brokerage involves the platform's configuration of the action of particular political actors ('brokers') through its composite features of visibilizing, ordering and curating content, allowing the brokers to advance a political agenda through historical revisionism. Platforms are political because they are in the business of governing people, objects and discourses within the boundaries of their infrastructures (Bucher, 2018). The product of such governance is its potentiality to construct new realities and political brokers take advantage of this by creating a network that builds, propagates, and cements their political narratives without being subjected to the same scrutiny of and by traditional gatekeepers. In other words, the brand of political brokerage that works through deception and fabrication might not be permissible in mainstream forms of media, but they thrive in platforms with porous governance structures.

Paying ethnographic attention to the working of the political brokerage process in the context of social media illuminates the broader structure that constructs political discourse in the present time. Brokers are visibilized and their content categorized-imbued with their personal (or politically motivated) interpretations of 
history and political vision-and as a result of this socio-technical interaction they are able to connect to viewers whose aspirations align with this vision, or whose political views can be shaped and fortified through sustained exposure to such content. The platform YouTube, through its algorithmic recommendation system and other affordances, can also be seen as a 'broker', functioning as a "middleman" (Lindquist, Xiang and Yeoh, 2012; Stovel and Shaw, 2012) that bridges the Filipino YouTube public to these brokers. This networked brokerage has important implications to the role of social media in examining political engagement in two ways.

First, it spotlights a particular category of (sub)political actors as part of an assemblage of the political brokerage process critical in understanding political interlocution in the contemporary context. Often dismissed simply as trolls or unimportant political actors, these YouTube brokers perform an important role of bridging citizens with political actors who can benefit, directly or indirectly, from the brokerage process. It is by appearing to possess 'in-group identification' and therefore seemingly 'biased' (Stovel and Shaw, 2012) toward ordinary citizens by presenting themselves as 'ordinary experts'-- 'political and historical commentators from the masses' --that their brokerage role assumes believability and legitimacy. As brokerage processes thrive within personally affective networks, the engagement of microinfluencer strategies allows the brokers to achieve a legitimate and relatable persona and facilitate affect and engagement crucial for the capturing of people's political aspirations within the context of the platform's attention logics. The power of this assemblage appears to be more potent in the context of the Philippines, which is characterized by constant political turbulence, a weak state, declining media trust, and a public that are simultaneously entertainment and politically savvy. While our research echoes the findings of other studies on the role of YouTube in promoting political influence (Lewis 
2019; Fisher and Taub, 2019), future studies may further examine the role of networked brokerage assemblages in advancing political narratives in other contexts or through other platforms.

Secondly, it illustrates the 'greyness' of political influence and historical knowledge construction. This networked assemblage constructs political influence by casting Marcos and the Martial Law period in a favorable light while negating the atrocities surrounding that period as evidenced by historical documents. This works to legitimizes a particular political narrative as knowledge and attempts to erase a turbulent period in history for a political agenda.

We show how political disinformation is embedded in the (techno)sociality of communication but most importantly, we emphasize and characterize the networked assemblage that makes this possible. Who gains from this political brokerage process? Highlighting the 'duality of the brokerage process' (Stovel and Shaw, 2012), this assemblage brings together and organizes disparate actors and political content amidst an overabundance of content on social media and the crevices in existing Philippine political infrastructures. The scope of the study does not allow us to affirm whether these YouTube brokers are part of disinformation infrastructures (although some evidence may signal an orchestrated strategy) or whether they are motivated by personal ideological leanings. Nonetheless, we argue that whether part of a disinformation architecture (Ong and Cabanes, 2018) or not, they are able to powerfully broker a political agenda that benefits particular political interests. The brokerage process attends to gaps in information by visibilizing preferred political narratives that are curated for a user's needs and personal political tastes, thereby allowing non-traditional political elites to become active political actors. In another way, this political brokerage process breeds legitimization of content 
into knowledge without accountability, while allowing the brokerage assemblage to gain economically from the process.

\section{Acknowledgements}

This project was supported by the Democracy and Disinformation Consortium/United

Nations Development Program under the project, Condition of the Freedom of Information in the Philippines. It benefitted from discussions during the conference, "BALIK KA/SAYSAY/AN": A Conference on Historical Revisionism in the Philippines, 21-25 September 2020.

\section{References}

Abidin C (2017) \#familygoals: family Influencers, calibrated amateurism, and justifying young digital labor. Social Media+ Society 3(2): 707191.

Abidin C (2015) Communicative Intimacies: Influencers and Perceived Connectedness. Ada: A Journal of Gender, New Media, and Technology, 8: 1-16.

Aguilar FVJ (2019) Political conjuncture and scholarly disjunctures: Reflections on studies of the Philippine state under Marcos. Philippine Studies: Historical and Ethnographic Viewpoints 67(1): 3-30.

Agosti C et al. (2019) Algorithm exposed: Investigating YouTube personalization with yTREX. Available at: https://wiki.digitalmethods.net/Dmi/SummerSchool2019AlgorithmsExposed (accessed 11 April 2020).

Barbasi AL (2003) Linked. New York: Plume.

Bautista VF (2018) The pervert's guide to historical revisionism: Traversing the Marcos fantasy. Philippine Studies: Historical and Ethnographic Viewpoints 66(3): 273300. 
BiradorHQ (2020) ANG MGA NAGAWA NI PNOY SA ATING BANSA, MAS TAMANG TANUNG PALA EH MAY NAGAWA NGA BA SYA? \#birador Available at: https://www.youtube.com/watch?v=7yjS_hiEgN4 (accessed 17 March 2020).

Bucher T (2018) If...Then: Algorithmic Power and Politics. London: Oxford University Press.

Burgess J and Green J (2018) YouTube: Online Video and Participatory Culture. Cambridge: Polity.

Caliandro A and Gandini A (2017) Social network analysis. In: Qualitative Research in Digital Environments: A Research Toolkit. New York: Routledge, pp. 157-190.

Cheney-Lippold J (2011) A New Algorithmic Identity: Soft Biopolitics and the Modulation of Control. Theory, Culture \& Society, 28(6): 164-181.

Cohn J (2019) The Burden of Choice: Recommendations, Subversion, and Algorithmic Culture. New Jersey: Rutgers University Press.

Conway M (2017) Determining the Role of the Internet in Violent Extremism and Terrorism: Six Suggestions for Progressing Research. Studies in Conflict \& Terrorism, 40(1): 77-98.

Cooper P (2020) How Does the YouTube Algorithm Work? A Guide to Getting More Views. Hootsuite, 18 August. Available at: https://blog.hootsuite.com/how-theyoutube-algorithm-works/ (accessed 21 January 2021).

Dagle R and Fallorina R (2019). YouTube the new battleground for disinformation. Rappler, 16 August. Available at: https://www.rappler.com/thoughtleaders/237828-analysis-youtube-the-new-battleground-against-disinformation (accessed 15 March 2020). 
Deleuze G and Guattari F (1987) A thousand plateaus: Capitalism and schizophrenia. Minneapolis: University of Minnesota Press.

Duffy BE (2017) (Not) Getting Paid to Do What You Love: Gender, Social Media, and Aspirational Work. New Haven: Yale University Press.

Epimetheus (2018) Was Ferdinand Marcos a Villain or Hero? (History of the Philippines,

Marcos Biography). Available at: https://www.youtube.com/watch?v=5VTaLaevab4 (accessed 17 March 2020).

Fisher M and Taub A (2019). How YouTube Radicalized Brazil. The New York Times, 11 August. Available at: https://www.nytimes.com/2019/08/11/world/americas/youtube-brazil.html (accessed 15 March 2020).

Gillespie T (2014) The Relevance of Algorithms. In: Gillespie T, Boczkowski P and Foot K (eds) Media Technologies: Essays on Communication, Materiality, and Society. Cambridge: MIT Press, pp. 167-196.

Gillespie T (2017) Algorithmically recognizable: Santorum's Google problem, and Google's Santorum problem. Information, communication \& society 20(1): 6380.

Gillespie T (2018) Custodians of the internet: Platforms, content moderation, and the hidden decisions that shape social media. New Haven: Yale University Press.

Jamieson KL (2018) Cyberwar: How Russian Hackers and Trolls Helped Elect a President; What We Don't, Can't, and Do Know. New York: Oxford University Press.

Jenkins H (2006) Fans, Bloggers, and Gamers: Exploring Participatory Culture. New York: New York University Press. 
Khamis S, Ang L and Welling R (2016) Self-branding, 'microcelebrity' and the rise of social media influencers. Celebrity Studies 8(2):191-208.

Lewis R (2018) Alternative influence: Broadcasting the reactionary right on YouTube. Report, Data \& Society.

Lindquist J, Xiang B and Yeoh B (2012) Introduction: Opening the Black Box of Migration: Brokers, the Organization of Transnational Mobility and the Changing Political Economy in Asia. Pacific Affairs 85(1): 7-19.

Lobato R (2016) The cultural logic of digital intermediaries: YouTube multichannel networks. Convergence 22(4), 348-360.

Madden M, Lenhart A, and Fontaine C (2017) How youth navigate the news landscape. Report, Data \& Society.

Marwick A (2015). You May Know Me from YouTube: (Micro)-Celebrity in Social Media. In: Marshall PD and Redmond S (eds) A Companion to Celebrity. Hoboken, NJ: Wiley Blackwell, pp. 333-350.

McKay M and Perez P (2019) Citizen aid, social media and brokerage after disaster. Third World Quarterly 40:10: 1903-1920.

Mandrilla K and Punongbayan K (2016) Marcos years marked 'golden age' of PH economy? Look at the data. Rappler, 05 March. Available at: https://www.rappler.com/voices/imho/marcos-economy-golden-age-philippines (accessed 23 May 2020).

Mercurio R (2019) Philippines among top markets for YouTube. Philstar Global, 28 July. Available at: https://www.philstar.com/business/2019/07/28/1938388/philippines-amongtopmarkets-youtube (accessed 15 March 2020). 
Mijares P (1976) The conjugal dictatorship of Ferdinand and Imelda Marcos. San Francisco: Union Square Publications.

Muller B (2020) How Search Engines Work: Crawling, Indexing, and Ranking. Available at: $\quad$ https://moz.com/beginners-guide-to-seo/how-search-engines-operate (accessed 4 June 2020).

Nowak TC and Snyder KA (1974) Clientelist politics in the Philippines: Integration or instability? American Political Science Review 68(3): 1147-1170.

Official Gazette. (2015). The Fall of the Dictatorship. Philippine Government, 25 February. Available at: https://www.officialgazette.gov.ph/featured/the-fall-ofthe-dictatorship/ (accessed 23 May 2020).

Ong, JC and Cabañes JVA (2018) Architects of networked disinformation: Behind the scenes of troll accounts and fake news production in the Philippines. Report, Newton Tech4Dev Network.

Ong JC, Tapsell R, and Curato N (2019). Tracking Digital Disinformation in the 2019 Philippine Midterm Election. Report, The New Mandala, August.

Patton P (1994) Metamorpho-logic: Bodies and powers in A Thousand Plateaus. Journal of the British Society for Phenomenology: 25(2): 157-169.

Pertierra R (2016) Anthropology and the AlDub Nation Entertainment as Politics and Politics as Entertainment. Philippine Studies: Historical \& Ethnographic Viewpoints 64(2):289-300.

Postigo H (2014) The socio-technical architecture of digital labor: converting play into YouTube money. New Media \& Society 18: 332-349.

Rieder B, Matamoros-Fernández A and Coromina Ò (2018) From ranking algorithms to 'ranking cultures': Investigating the modulation of visibility in YouTube search results. Convergence 24(1): 50-68. 
Rogers R (2013) End of the virtual: Digital Methods. In: Digital Methods. Cambridge: MIT Press, pp. 19-38.

Sangkay Janjan TV (2019) KUNG NATULOY ANG PLANO NI MARCOS, HIGIT PA SA AMERIKA ANG PILIPINAS. Available at: https://www.youtube.com/watch?v=ZaTbvBdYVUg (accessed 17 March 2020).

Scott JC (1972) Patron-client politics and political change in Southeast Asia. The American political science review 66(1): 91-113.

Seagrave S (1988) The Marcos Dynasty. New York: Harper \& Row.

Sucio P (2019) YouTube as Political Influencer Takes the Spotlight. Tech News World,

16 May. Available at: https://www.technewsworld.com/story/86188.html (accessed 15 March 2020).

Utz S and Wolfers L (2020) How-to videos on YouTube: The role of the instructor. Information, Communication \& Society August 2020: 1-16.

We Are Social (2018) Digital in 2018 Global Overview. Available at: https://www.slideshare.net/wearesocial/digital-in-2018-global-overview$\underline{86860338}$ (accessed 15 March 2020). 